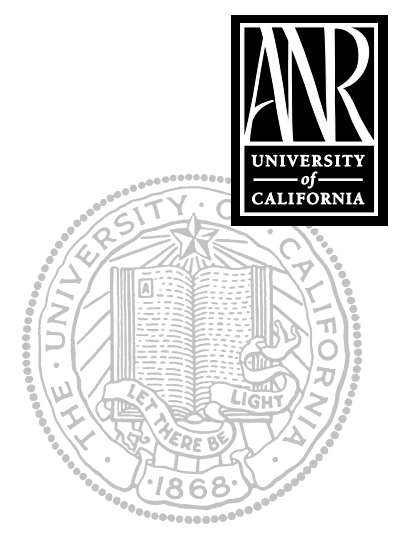

UNIVERSITY OF CALIFORNIA

Division of Agriculture and Natural Resources

http://anrcatalog.ucdavis.edu

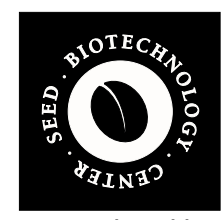

Seed Biotechnology Center, UC Davis http://sbc.ucdavis.edu

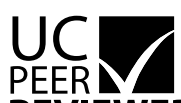

REVIEWED

\title{
Production of Therapeutic Proteins in Plants
}

BRUCE R. THOMAS, Researcher, Seed Biotechnology Center, University of California, Davis; ALLEN VAN DEYNZE, Biotechnology Specialist, Seed Biotechnology Center, University of California, Davis; KENT J. BRADFORD, Professor of Vegetable Crops and Director, Seed Biotechnology Center, University of California, Davis

\section{INTRODUCTION}

Until recently, pharmaceuticals used for the treatment of diseases have been based largely on the production of relatively small organic molecules synthesized by microbes or by organic chemistry. These include most antibiotics, analgesics, hormones, and other pharmaceuticals. Increasingly, attention has focused on larger and more complex protein molecules as therapeutic agents. Proteins are large molecules composed of long chains of subunits called amino acids (see Suslow, Thomas, and Bradford 2002). Just as words are composed of the 26 letters of the alphabet, proteins are composed of different combinations of the 20 or so amino acids, except that the length of proteins is often 100 to 1,000 amino acids ("letters") long. The structure and functionality of a given protein is determined by its sequence of amino acids, which, in turn, determines its three-dimensional conformation, or structure. Internal bonds (sulfur and hydrogen bonds) among the amino acids give the protein its final shape and form. Complex proteins undergo further processing such as the addition of phosphate groups (phosphorylation) or carbohydrate molecules (glycosylation), which modify the proteins' functions. Information stored in DNA directs the protein-synthesizing machinery of the cell to produce the specific proteins required for its structure and metabolism. Since proteins play critical roles in cell biology, they have many potential therapeutic uses in preventing and curing diseases and disorders. The first protein used to treat disease was insulin, a small peptide that revolutionized the treatment of diabetes. In addition, the antigens used in vaccinations to induce immune responses are often proteins.

While short peptide chains (containing fewer than 30 amino acids) can be synthesized chemically, larger proteins are best produced by living cells. The DNA that encodes the instructions for producing the desired protein is inserted into cells, and as the cells grow they synthesize the protein, which is subsequently harvested and purified. Since 1982, more than 95 therapeutic proteins, or peptides ("biologics"), have been licensed for production using bacterial, fungal, and mammalian cells grown in sterile cultures, and hundreds of additional therapeutic proteins are currently being developed and tested. In fact, many analysts anticipate that in the near future the capacity of cell culture facilities will fall far short of demand, as augmenting cell culture facilities requires large investments in buildings and equipment. Recently, transgenic (i.e., plants engineered to produce specific proteins) plant expression systems (Suslow, Thomas, and Bradford 2002) were developed as alternative sources for the production of biologics, known as plant-made pharmaceuticals, or PMPs. In general, the use of plants means a lower cost of production and easier expansion for large-volume production than cell culture systems. Instead of a large capital investment in cell culture facilities, plant production systems can be expanded simply by growing and harvesting additional plants. However, about 50 percent of the total cost of production is in extraction and purification of the proteins, which is required in both systems. This reduces the potential cost advantage for PMPs. 
Nonetheless, plant expression systems can potentially produce hundreds of kilograms per year of a purified protein whereas the cost of a similar production capacity using mammalian cell cultures may be prohibitive.

Like mammalian cells, plant production systems have the advantage over microbial systems of being able to produce active forms of complex proteins with appropriate post-translational modifications (e.g., glycosylation). However, mammalian cells used for the production of biologics must be managed carefully to avoid unintentional transmission of viral diseases that infect humans; this is not a risk for biologics produced in plant systems. Nevertheless, production of proteins using plant expression systems poses some unique challenges, such as containment to prevent gene transfer to conventional crops during plant growth and possibly higher costs to extract the desired protein due to the presence of interfering compounds in plants.

This publication describes the types of biologics produced in plants, the plantbased production systems in use, the government agencies responsible for regulation of biologics, and some agricultural practices that are required to safely produce biologics in crop plants.

\section{UNIVERSITY OF CALIFORNIA RESEARCH HIGHLIGHTS}

Bob Buchanan and Peggy Lemaux, Department of Plant and Microbial Biology, University of California, Berkeley, are studying the use of thioredoxin to decrease the allergenicity and increase the digestibility of foods. Food allergies continue to be a major problem worldwide. The magnitude of the problem becomes apparent when one considers that 2 percent of the total population shows clinical symptoms of the problem, and up to one-third of all adults believe they have food allergies. Buchanan and Lemaux have begun to address the problem using a ubiquitous protein, thioredoxin. When milk and wheat preparations are treated in vitro with thioredoxin, they became less allergenic. Buchanan and Lemaux are currently attempting to lower allergenicity in wheat and other grains by enriching thioredoxin in the starchy part of the grain with the use of a strong promoter to drive its expression specifically in the protein storage organelles. The modified grain has been successfully grown for several generations in the greenhouse and most recently in the field. The thioredoxin-enriched grains are now being analyzed for allergenic as well as digestibility properties. The results obtained so far indicate that it may be possible to obtain wheat that shows decreased allergenicity and increased digestibility. For more information please refer to http://www.aspb.org/downloads/foodallerg.pdf

Bo Lonnerdal at the Department of Nutrition, University of California, Davis, studies the biological activity of anti-infective and nutritional human milk proteins produced in rice seeds. Incorporation of these proteins into transgenic food crops may help to prevent human diseases and improve human nutrition. These proteins may be particularly useful in rice-based infant formulas by providing important components normally found in human milk for infants that cannot be breastfed. 


\section{THERAPEUTIC PROTEINS}

\section{Antibodies}

Passive immunizations using monoclonal antibodies are the largest category of biotechnology-derived drugs. They are a result of the development of humanized antibodies that do not activate an immune response when administered. In passive immunization, rather than injecting an antigen and inducing the body to produce antibodies against it, an antibody targeted toward the specific antigen is administered directly as a therapeutic. For example, multiple doses of Herceptin, a monoclonal antibody effective against breast cancer, are introduced intravenously to patients to boost the body's ability to suppress the cancer cells. Antibody therapies for non-Hodgkin's lymphoma, rheumatoid arthritis, and respiratory syncytial virus have been approved for use in recent years. Clinical trials are underway for hundreds of additional antibody drugs directed against various cancers, heart disease, infectious diseases, inflammation, transplantation rejection, and skin, blood, neurological, respiratory, allergic, and autoimmune disorders. The annual market for these antibody drugs may grow to $\$ 8$ billion by 2004 .

Transgenic plants have been used for the production of antibodies directed against dental caries, rheumatoid arthritis, cholera, E. coli diarrhea, malaria, certain cancers, Norwalk virus, HIV, rhinovirus, influenza, hepatitis B virus, and herpes simplex virus. Some of these have demonstrated preventative or therapeutic value and are currently in clinical trials. The most advanced product to date is an antiStreptococcus mutans secretory antibody for the prevention of dental caries that is currently in Phase II clinical trials. Plants offer the only viable, large-scale production system for this antibody (Gavilondo and Larrick 2000, Larrick and Thomas 2001). Links to further information and a comprehensive table of antibody targets in clinical trials can be accessed through the Seed Biotechnology Center at the University of California, Davis. (See "For Additional Information," below.)

\section{Vaccines}

Protein antigens from various pathogens have been expressed in plants and used to produce immune responses resulting in protection against diseases in humans. Plant-derived vaccines have been produced against Vibrio cholerae, enterotoxigenic E. coli, hepatitis B virus, Norwalk virus, rabies virus, human cytomegalovirus, rotavirus, and respiratory syncytial virus F. Insulin expression in plants produced a vaccine useful for protection against insulin-dependent autoimmune mellitus diabetes. Plant virus particles expressing multiple antigens from various pathogens have been useful as vaccines against pulmonary infections of Pseudomonas aeruginosa, opportunistic infections of Staphylococcus aureus, malaria, HIV, hepatitis B virus, and respiratory syncytial virus F. A company in California has developed a virus-based system in tobacco to produce personalized vaccines against cancer. Antigens specific to an individual patient's tumor are expressed in tobacco, harvested, purified, and administered to the patient. This entire process can take as little as 4 weeks, compared to 9 months for the same process using mammalian cell culture.

Many of these plant-derived antigens were purified and used as injectable vaccines, but oral delivery of these vaccines within foods has also been successful. Edible vaccines may be particularly valuable as a low-cost delivery mechanism for immunization against various diseases in developing countries. They circumvent the need for injections and sterile needles and do not require refrigeration. Edible vaccines have successfully immunized test animals against enterotoxigenic E. coli, 
Vibrio cholerae, hepatitis B virus, Norwalk virus, rabies virus, respiratory syncytial virus $\mathrm{F}$, and rotavirus. The concentration of vaccine proteins produced in edible plant tissues is currently relatively low. Research is underway to increase the production of vaccine in targeted plant tissues that are best for human consumption. The choice of crop is also important. Edible vaccines are being tested in potatoes, tomatoes, bananas, and carrots. Potatoes are usually cooked for consumption, which may inactivate the vaccine. Short storage life and length of production cycle may hinder vaccine production in tomatoes and bananas. Carrots have few storage problems and can be eaten raw, and carrots modified to produce the antigen used in hepatitis B vaccines are currently entering preclinical trials.

Although several challenges need to be overcome, including standardizing expression and dosage levels and immune responses to food-based vaccines, several products are currently undergoing clinical testing. It is not anticipated that such edible vaccines would ever be marketed through standard food distribution channels. Rather, they would be distributed through health service channels to be consumed under the supervision of health professionals. Nonetheless, edible vaccines could greatly reduce the cost of immunizing children in many parts of the world. While not strictly a disease, vitamin A deficiency affects over 120 million children, causing blindness and 1 to 2 million deaths each year in countries where rice is the primary staple food. Rice seeds have been engineered to synthesize and accumulate beta-carotene, which is converted into vitamin A in the body. This Golden Rice is being developed into commercial cultivars at the International Rice Research Institute to help alleviate vitamin A deficiency.

\section{Other Proteins}

Plants have been tested as production systems for a range of therapeutic proteins to be used either directly in foods or after purification. Expression in plants of milk proteins such as lactoferrin and beta-casein may contribute the therapeutic values of these proteins to other food products. Expression of thioredoxin in foods such as cereal grains would increase the digestibility of proteins and thereby reduce their allergenicity. (See page 2, "University of California Research Highlights.") Other proteins that have potential therapeutic applications after expression and purification from plants are listed in table 1 .

\section{PROTEIN EXPRESSION SYSTEMS}

To achieve specific protein production in plants, the DNA that encodes the desired protein must be inserted into the plant cells. This can be done as a stable transformation when foreign DNA is incorporated into the genome of the plant. A promoter associated with the inserted DNA then directs the cells to produce the desired protein, often targeting it to accumulate only in specific tissues such as the seed. Alternatively, a plant virus can be used to direct expression of a specific protein without genetically modifying the host plant. The transformation and expression systems used to engineer these proteins in plants affect the stability, yield, cost of purification, and quality of the proteins produced. In addition, the methods used affect the procedures needed to prevent the spread of the engineered traits to other plants during their growth in the field.

\section{Plant Transformation Systems}

Foreign genes may be inserted, or transformed, into plants via a number of methods. Stable transformation into the nuclear genome is done primarily using Agrobacteriummediated transformation or particle bombardment methods (Suslow, Thomas, and Bradford 2002). In each case, the DNA coding for the protein of interest and an associated promoter to target its expression to a particular tissue or developmental stage is integrated into the genome of the plant. Thus, when the plant is propagated, each plant 
Table 1. The production in transgenic plants of biopharmaceuticals for human health

\begin{tabular}{|c|c|c|}
\hline $\begin{array}{l}\text { Potential application or } \\
\text { human protein }\end{array}$ & Plant host & Protein \\
\hline anticoagulant & tobacco & protein C \\
\hline thrombin inhibitor & canola (Brassica napus) & hirudin \\
\hline neutropenia & tobacco & $\begin{array}{l}\text { granulocyte-macrophage } \\
\text { colony-stimulating factor }\end{array}$ \\
\hline growth hormone & tobacco & somatropin, chloroplast \\
\hline anemia & tobacco & erythropoietin \\
\hline antihyperanalgesic by opiate activity & arabidopsis & enkephalins \\
\hline $\begin{array}{l}\text { wound repair and control of } \\
\text { cell proliferation }\end{array}$ & tobacco & epidermal growth \\
\hline hepatitis $C$ and $B$ & $\begin{array}{l}\text { rice, turnip } \\
\text { tobacco }\end{array}$ & $\begin{array}{l}\text { interferon- } \alpha \\
\text { interferon- } \beta\end{array}$ \\
\hline liver cirrhosis, burns, surgery & tobacco & serum albumin \\
\hline blood constitute & tobacco & hemoglobin $\alpha, \beta$ \\
\hline collagen & tobacco & homotrimeric collagen \\
\hline cystic fibrosis, liver disease & rice & $\begin{array}{l}\alpha-1 \text { antitrypsin trypsin inhibitor for } \\
\text { transplant surgery maize aprotinin }\end{array}$ \\
\hline antimicrobial & potato & lactoferrin \\
\hline \multicolumn{3}{|l|}{ Non-human proteins } \\
\hline hypertension & tobacco, tomato & angiotensin-converting enzyme \\
\hline HIV therapies & tobacco & $\begin{array}{l}\alpha \text {-tricosanthin from TMV-U1 sub-genomic } \\
\text { coat protein }\end{array}$ \\
\hline Gaucher's disease & tobacco & glucocerebrosidase \\
\hline
\end{tabular}

Source: Daniell, Streatfield, and Wycoff 2001.

will transmit this property to its progeny and large numbers of plants containing the transferred gene are readily generated. It is also possible to deliver genes into the separate genome of plastids (chloroplasts and mitochondria) in plant cells. As plants have multiple copies of chloroplasts per cell, chloroplast transformation has the potential for high expression levels and high yields of recombinant proteins. Chloroplast transformation has been successful in tobacco and potato, and research is being done to expand to other crops. Because genes in chloroplast genomes are not transmitted through pollen, recombinant genes are easier to contain, thereby avoiding unwanted escape into the environment.

\section{Viral Expression Systems}

A second method of engineering plant protein expression is transduction, the use of a recombinant plant virus to deliver genes into plant cells. The DNA coding for the desired protein is engineered into the genome of a plant virus that will infect a host plant. A crop of the host plants is grown to the proper stage and is then inoculated with the engineered virus. As the virus replicates and spreads within the plant, many copies of the desired DNA are produced and high levels of protein production are achieved in a short time. The entire plant is then harvested to extract the protein. This method does not result in the transfer of DNA into the plant genome, and the viral particles are generally excluded from pollen and egg cells, so the recombinant 
DNA is not transmitted to progeny via pollen or seeds. In addition, the viruses used in this system are poor competitors with natural viruses, and over time they will eliminate the introduced genes from their genome, so the risks of escape and survival of the modified virus in the environment are quite low. A limitation with this system is that the green plant matter must be processed immediately after harvest and cannot be stored.

\section{Promoter and Targeting Systems}

A variety of constitutive (e.g., 35S cauliflower mosaic promoter) and developmentally regulated (e.g., napin in Brassica seed, $\alpha$-amylase in monocot seed) promoters have been used to achieve high-level expression of therapeutic proteins in plants. In addition, signal sequences can target proteins to accumulate in specific compartments in plant cells. This may be important for proper folding to produce an active protein or to enable (or prevent) post-translational modifications such as glycosylation in the endoplasmic reticulum. Glycosylation (addition of specific sugars to proteins) of biologics may be important for their structure, function, and efficacy. Protein glycosylation in plants is often similar to that in mammals, but some differences may occur. Glycosylation does not appear to influence the effectiveness of antibodies, but it may affect the in vivo stability or allergenicity of a PMP when used as a human therapeutic (Bardor et al. 1999).

Compartmentalization within the cell or tissue can affect protein stability and purification procedures. Protein secretion into the extracellular space or localization in seed oil bodies may enable the protein to be purified more readily. Targeting protein production to the seed is advantageous as seeds can accumulate large amounts of protein that can be stored after harvest in the dry seeds while maintaining protein integrity. In addition, since germinated (malted) grains are the source of many industrial enzymes, procedures for extraction of proteins from seeds are well established. In general, however, the efficiency and cost of large-scale purification and extraction of the expressed proteins are important considerations in selecting a PMP expression system. This makes edible vaccines or therapeutics attractive as purification may be avoided entirely. Edible vaccines and proteins must be designed to have sufficient stability to pass through the digestive tract and still be available for absorption in their active form.

\section{PRODUCTION OF PHARMACEUTICAL CROPS}

\section{Regulatory Oversight}

The U.S. Department of Agriculture (USDA) regulates the production of PMPs and defines appropriate safeguards for the growth and transport of seeds and harvested plants of regulated products through the Animal and Plant Health Inspection Service (APHIS). It also regulates PMPs involved in animal health through the Center for Veterinary Biologics (CVB). The Food and Drug Administration (FDA) Center for Biologics Evaluation \& Research (CBER) regulates all biologics, from research to commercialization. Additionally, the Center for Drug Evaluation \& Research (CDER) regulates those biologics or PMPs that are drug related, from research to commercialization in the United States. A joint USDA-FDA document was issued in May, 2002, to guide the industry on regulatory considerations for PMPs (for updated links, see http://sbc.ucdavis.edu/). Unlike other transgenic crops that may be deregulated after sufficient data are available on their safety, PMPs are always grown under APHIS permit and are regulated concurrently by the FDA and the USDA. 


\section{Production Practices}

Unlike conventional crops, PMPs are grown under a closed system that is regulated by government agencies and controlled completely by the technology provider and manufacturer. APHIS regulates the interstate movement and environmental release of plants engineered for production of PMPs. CBER regulates the manufacturing of PMPs and considers fields of pharmaceutical crops to be "factories." The technology provider must obtain a permit from APHIS to produce the PMP and contracts in advance with farmers to grow the crop. It is the responsibility of technology providers and manufacturers to document the required crop management practices, to maintain containment of seed, pollen, or any plant product, and to ensure that Good Agricultural Practices (GAP) and Good Manufacturing Practices (GMP) are followed. Applicants must specify their procedures for maintaining control of the crop during planting, harvesting, and disposal of crop residues and crop volunteers in following seasons to ensure that these plants do not enter the human food supply. These procedures include stringent cleaning of all planting and harvesting equipment when switching to a different crop variety. GAP are also recommended to reduce microbial contamination in harvested crop products. GMP are required to ensure controls for safety, consistency, and potency of PMPs. GMP procedures include standards for quality management, personnel training, buildings and facilities, process equipment, documentation and records, materials management, production and in-process controls, packaging and labeling for transport, storage and distribution, laboratory controls, and process validation.

Production practices for PMPs are modeled after, but are more stringent than, procedures used for seed production (fig. 1). Foundation and Certified seed production requires management practices designed to maintain seed genetic purity by preventing unwanted transmission of pollen in the field or mechanical mixing of seed during harvesting, processing, and distribution. To prevent pollen transfer to neighboring crops, physical isolation distances from other fields of the same species are far greater for PMPs than those required by the Association of Official Seed Certifying Agencies for production of Foundation seed (USDA APHIS 2002).The pollination mechanisms of the plants determine isolation requirements. The enclosed flower structures of self-pollinating crops like rice, barley, and soybean naturally provide good pollen containment, so the risk of pollen spread from these crop species is minimal and isolation distances are relatively short (e.g., $100 \mathrm{ft}$ for rice and $500 \mathrm{ft}$ for barley). Corn, however, produces great quantities of wind-dispersed pollen, so pharmaceutical-producing plants must be isolated by at least 1 mile $(1.6 \mathrm{~km})$ from other seed corn fields and by shorter distances from commercial corn fields, depending upon what additional steps are taken to limit pollen distribution. Since the pollen-producing parts of the corn plant (tassels) are separate from the seed-producing parts of the plant (ears), pollen containment can be further managed by manual removal of tassels or by using male-sterile varieties that do not produce viable pollen. Crops that are pollinated by bees, that produce dormant seeds, or that can crosspollinate with related wild species growing in the area are not recommended for PMP production. Temporal isolation can be achieved by planting the pharmaceutical crop at a different time than the nearest related food crops so the two do not overlap in their times of pollination. Planting nontransgenic border rows around the pharmaceutical crop can further enhance containment of pollen and is generally required. PMPs expressed in leaves can be harvested before the plants develop any flowers, thereby preventing any possibility of pollen release. Plastid transformation may be used to provide containment in the future because transgenes engineered into the plastid genome will have little or no transmission via pollen. Containment of genes engineered into plant viruses is based on physical isolation, borders of nonhost plants, planting of virus-resistant cultivars if any crops of the same species are grown nearby, and the observation that introduced genes are deleted rapidly when the virus propagates in the wild. 


\section{Foundation or Certified Seed}

Initial seed of high genetic purity provided by breeder or seed company.

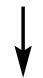

Application to seed certifying agency, but no permit required.

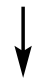

Contract with farmer to produce seed.

Certifying agency inspects field for previous crop history, isolation requirements, genetic purity, weeds, diseases, etc., as specified for the class of Foundation or Certified seed.

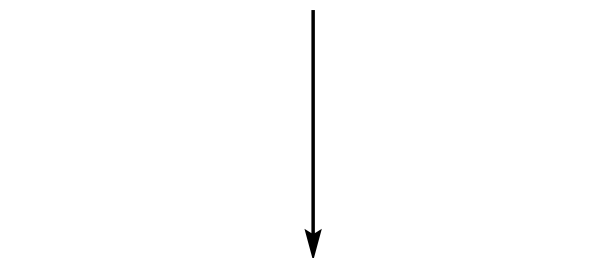

Harvest and conveyance equipment cleaned and inspected prior to harvest.

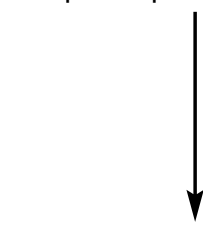

Identity of seed lots maintained during harvest and transport.

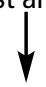

Storage bins and seed conditioning facility cleaned and inspected prior to storing or cleaning seed.

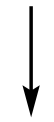

Testing for genetic purity, presence of weed seeds, diseases, etc.

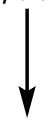

Labeling and tagging to ensure identity preservation in marketing channels as a class of certified seed.

\section{Plant-Made Pharmaceuticals (PMPs)}

Seed engineered for protein production provided by technology developer.

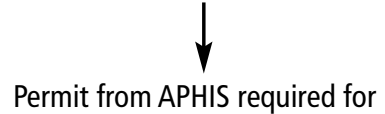
field production of PMPs.

Contract with farmer to produce PMP crop.

Technology provider ensures that protocols for isolation, containment, etc., specified in

APHIS permit are met. Standards are about 10 times more stringent than for Foundation seed.

Good Agricultural Practices (GAP) and Good Manufacturing Practices (GMP) (protocols, record keeping,

etc.) are used to meet FDA requirements.

Harvest and conveyance equipment cleaned and inspected prior to harvest.

Trucks and bins are covered to prevent any loss of seed or plant material in transport.

Identity of seed or plant materials maintained during harvest and transport.

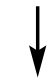

Material received at processing plant; GMP protocols followed during purification to meet pharmaceutical standards.
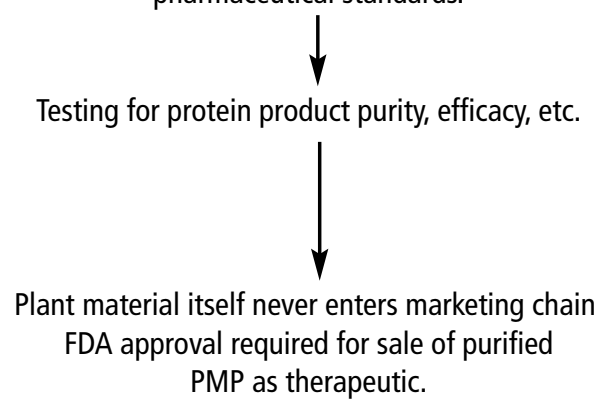

Figure 1. Comparison of production procedures for Foundation and Certified seed and for PMPs. In both cases, isolation, identity preservation, monitoring, and recordkeeping requirements are more stringent than for the production of other agricultural commodities. 
Genetic use restriction technologies (GURT), or technology protection systems, are controversial for use in food crops, but these methods may be ideal to help with containment of pharmaceutical crops. GURT methods, such as the "Terminator" system, allow reversible control of plant fertility. This would enable fertile plants to be used for variety development and seed production under controlled conditions, but then the largest acreages for commercial production of PMPs could be planted with plants that cannot spread their genes via pollen or seed.

Strict identity preservation procedures are required throughout production, harvesting, and processing of pharmaceutical crops (Sundstrom et al. 2002). This is relatively straightforward for small-scale production in greenhouses or small plots. However, the potential market for plant-derived biologics could result in tens of thousands of acres of pharmaceutical crops, making identity preservation more challenging. Procedures to ensure the proper containment and channeling of these products will be essential.

\section{CONCLUSIONS}

Production of pharmaceuticals in plants for therapeutic purposes shows great promise, with some PMPs in clinical trials and many others under investigation. Plant production systems are easily expanded and typically provide a lower cost of production relative to the cell culture systems currently used to produce biological therapeutics. Government agencies in the United States are actively developing the agronomic and manufacturing regulations needed to ensure safety, consistency, and potency of plant-made pharmaceuticals.

\section{REFERENCES CITED}

Bardor, M., L. Faye, and P. Lerouge. 1999. Analysis of N-glycosylation of recombinant glycoproteins produced in transgenic plants. Trends in Plant Sci. 4: 376-380.

Daniell, H., S. J. Streatfield, and K. Wycoff. 2001. Medical molecular farming: Production of antibodies, biopharmaceuticals, and edible vaccines in plants. Trends in Plant Sci. 6: 219-226.

Gavilondo, J. V., and J. W. Larrick. 2000. Antibody engineering at the millennium. Biotechniques 29: 128-145.

Larrick, J. W., and D. W. Thomas. 2001. Producing proteins in transgenic plants and animals. Cur. Opinion in Biotech. 12: 411-418.

Sundstrom, F. J., J. Williams, A. Van Deynze, and K. J. Bradford. 2002. Identity preservation of agricultural commodities. Oakland: University of California Division of Agriculture and Natural Resources, Publication 8077. http://anrcatalog.ucdavis.edu

Suslow, T. V., B. R. Thomas, and K. J. Bradford. 2002. Biotechnology provides new tools for planting. Oakland: University of California Division of Agriculture and Natural Resources, Publication 8043. http://anrcatalog.ucdavis.edu

USDA APHIS (Animal and Plant Health Inspection Service). 2002. Summary of the confinement measures for organisms being field tested in 2002. http://www.aphis.usda.gov/ppq/biotech/pdf/pharm-2002.pdf 


\section{GL OSSARY}

Allergen. An antigen that provokes an immune response.

Amino acids. Small molecules containing amino and carboxyl groups and variable side chains that can link together via peptide bonds to form proteins.

Antibody. An immunological protein produced by the lymphocytes in response to contact with an antigen. Each antibody recognizes just one antigenic determinant of one antigen and acts by specifically binding to it, thus rendering it harmless. Those from the IgG antibody class are found in the bloodstream and are used in immunoassay. Synonym: immunoglobulin.

Antigen. A macromolecule (usually a protein foreign to the organism) that elicits an immune response on first exposure to the immune system by stimulating the production of antibodies specific to its various antigenic determinants. During subsequent exposures, the antigen is bound and inactivated by these antibodies. Synonym: immunogen.

Autoimmune disease. A disease in which the body produces an immunogenic (i.e., immune system) response to some constituent of its own tissue.

Biologics. Agents, such as vaccines, that give immunity to diseases or harmful biotic stresses.

Constitutive promoter. An unregulated promoter that allows for continual transcription of its associated gene.

Glycosylation. The covalent addition of sugar or sugar-related molecules to other classes of molecule, including proteins or nucleic acids.

Humanized antibody. An antibody that is produced by using genetic engineering to selectively replace components of antibodies-including much of their antigen-binding regions-that are produced in other species with human proteins. This is done to prevent an immune response when the antibodies are introduced into humans for therapeutic purposes.

Immune response. The processes, including the synthesis of antibodies, that are used by vertebrates to respond to the presence of a foreign antigen.

Inducible promoter. The activation of a promoter in response to either the presence of a particular compound (i.e., the inducer) or to a defined external condition (e.g., elevated temperature).

Monoclonal antibody. An antibody, produced by a hybridoma cell, directed against a single antigenic determinant of an antigen.

Passive immunization. An immune response (to a pathogen) that results from injecting another organism's antibodies into the organism that is being challenged by the pathogen.

Peptide bonds. Chemical bonds that link together amino acids.

Peptides. Relatively small chains of amino acids are referred to as peptides; proteins are called polypeptides because they are composed of long chains of amino acids.

Phosphorylation. The addition of a phosphate group to a compound.

Plant-made pharmaceuticals (PMPs). Pharmaceutical substances in plants that have been genetically modified to express a therapeutic protein or molecule.

Post-translational modification. The addition of specific chemical components to a protein after it has been synthesized. Common modifications are the addition of phosphate groups (phosphorylation) and sugars (glycosylation).

Promoter. A short DNA sequence, usually adjacent to the relevant coding sequence, to which RNA polymerase binds before initiating transcription. This binding aligns the RNA polymerase so that transcription will initiate at a specific site. The nucleotide sequence of the promoter determines the tissue location, the timing, and the quantity of expression of the associated gene during development. 
Protein. A macromolecule composed of one or more polypeptides, each comprising a chain of amino acids linked by peptide bonds.

Stable transformation. Long-standing activity of a transgene following its introduction into target tissue. Stable expression usually implies integration of the transgene into the host genome.

Therapeutic protein. A protein that acts as a bioactive to counteract disease or physiological disorder.

Transcription. Synthesis of RNA from a DNA template via RNA polymerase.

Transduction. The transfer of a DNA sequence from one cell to another by means of a viral vector.

Transformation. The uptake and integration of DNA in a cell, in which the introduced DNA is intended to change the phenotype of the recipient organism in a predictable manner.

Transgenic. A living organism containing DNA transferred to it via recombinant DNA techniques.

Transient expression. Short-term activity of a transgene following its introduction into target tissue. Transient expression usually implies that the transgene is not integrated into the host genome.

Translation. The process of polypeptide synthesis in which the amino acid sequence is determined by mRNA, mediated by tRNA molecules, and carried out on ribosomes.

Vaccine. A preparation of dead or attenuated (weakened) pathogens, or of derived antigenic determinants, that can induce the formation of antibodies in a host, thereby producing host immunity against the pathogen. 


\section{FOR ADDITIONAL INFORMATION}

For updated information on PMPs and regulations: http://sbc.ucdavis.edu ABC Series, Agricultural Biotechnology in California. http://sbc.ucdavis.edu

Galun, Esra, and Eithan Galun. 2001. The manufacture of medical and health products by transgenic plants. Imperial College Press. http://www.icpress.co.uk/

Production of Therapeutic Proteins in Plants, Biotechnology Resource Series. http://sbc.ucdavis.edu

UCBiotech, University of California, Berkeley. http://ucbiotech.org

UC Davis Seed Biotechnology Center. One Shields Avenue, Davis, CA 95616. (530) 754-7333; FAX (530) 754-7222. http://sbc.ucdavis.edu

University of California Division of Agriculture and Natural Resources. Online catalog. http://anrcatalog.ucdavis.edu

For information about ordering other ANR Communication Services publications, slide sets, videos, and CD-ROMS, please contact

University of California

Agriculture and Natural Resources

Communication Services

6701 San Pablo Avenue, 2nd Floor

Oakland, CA 94608-1239

Telephone: (800) 994-8849 or (510) 642-2431

FAX: (510) 643-5470

E-mail inquiries: danrcs@ucdavis.edu

Visit the ANR Communication Services website at http://anrcatalog.ucdavis.edu

Publication 8078

C2002 by the Regents of the University of California

Division of Agriculture and Natural Resources

All rights reserved.

Produced by the Seed Biotechnology Center, UC Davis, in cooperation with the Biotechnology Workgroup of the UC Division of Agriculture and Natural Resources.

The University of California prohibits discrimination against or harassment of any person employed by or seeking employment with the University on the basis of race, color, national origin, religion, sex, physical or mental disability, medical condition (cancer-related or genetic characteristics), ancestry, marital status, age, sexual orientation, citizenship, or status as a covered veteran (special disabled veteran, Vietnam-era veteran or any other veteran who served on active duty during a war or in a campaign or expedition for which a campaign badge has been authorized). University Policy is intended to be consistent with the provisions of applicable State and Federal laws. Inquiries regarding the University's nondiscrimination policies may be directed to the Affirmative Action/Staff Personnel Services Director, University of California, Agriculture and Natural Resources, 300 Lakeside Drive, 6th floor, Oakland, CA 94612-3550; (510) 987-0096. For information about downloading this publication, telephone (530) 754-5112.

To simplify information, trade names of products have been used. No endorsement of named or illustrated products is intended, nor is criticism implied of similar products that are not mentioned or illustrated.

pr-12/02-GM/VFG

ISBN 978-1-60107-254-2

This publication has been anonymously peer reviewed for technical accuracy by University of California scientists and other qualified professionals. This review process was managed by the DANR Associate Editor for Farm Management and Economics. 